\title{
Combined effect of llizarov technique, low-intensity pulsed ultrasound, and teriparatide for limb reconstruction of Gustilo-Anderson type IIlc open tibial fracture with a large bone defect in elderly patients with severe osteoporosis: A case report
}

Koji Nozaka ( $\nabla$ kk-nozaka@mue.biglobe.ne.jp )

Akita University Graduate School of Medicine https://orcid.org/0000-0003-0238-8929

Naohisa Miyakoshi

Akita University Graduate School of Medicine School of Medicine: Akita Daigaku Daigakuin Igakukei Kenkyuka Igakubu

\section{Motoki Mita}

Akita University Graduate School of Medicine School of Medicine: Akita Daigaku Daigakuin Igakukei Kenkyuka Igakubu

Yoichi Shimada

Akita University Graduate School of Medicine School of Medicine: Akita Daigaku Daigakuin Igakukei Kenkyuka Igakubu

\section{Research Article}

Keywords: Gustilo-Anderson type Illc open tibial fracture, severe osteoporosis, llizarov external fixator

Posted Date: September 15th, 2021

DOl: https://doi.org/10.21203/rs.3.rs-906379/v1

License: (c) (1) This work is licensed under a Creative Commons Attribution 4.0 International License.

Read Full License 


\section{Abstract}

\section{Background}

Gustilo-Anderson type Illc tibial open fracture with large bone defects in severely osteoporotic elderly patients is a rare injury that may be a challenging clinical scenario.

\section{Case presentation}

This study presents the case of a 68-year-old man who sustained a Gustilo-Anderson type Illc open tibial fracture with a large bone defect. The patient had severe osteoporosis and the bone was contaminated; therefore, we determined that the bone could not be returned to the tibia. The patient underwent acute limb shortening and gradual lengthening with an llizarov external fixator combined with low-intensity pulsed ultrasound and teriparatide administration for limb reconstruction, which allowed immediate full weight-bearing capacity. The fixator was removed at 12 months postoperatively, and by this time, the fracture had completely healed. At the most recent 5-year follow-up after the injury, the patient reported fully weight-bearing capacity without walking aids and had full knee and ankle range of motion.

\section{Conclusions}

To the best of our knowledge, this is the first study to report the use of combined Ilizarov technique, lowintensity pulsed ultrasound, and teriparatide for limb reconstruction of Gustilo-Anderson type Illc open tibial fractures with large bone defects in elderly patients with severe osteoporosis.

\section{Background}

The incidence of open tibial fractures in the elderly is increasing due to the growing elderly population. Open tibial fractures with large bone defects are an increasing problem, and their treatment is challenging. Gustilo-Anderson type IIIc open tibial fractures with large bone defects are less common in elderly patients with severe osteoporosis than in young patients. However, the literature on the outcomes of open tibial fractures with large bone defects in elderly patients treated with modern techniques is limited.

\section{Case Presentation}

A 68-year-old man was injured while electrically reeling a wire rope on a fishing boat. Shortly after, the patient was transported to our hospital's emergency room. On clinical examination, two large soft-tissue defects were observed in the medial left ankle (Figure 1). The patient's left foot was pale, and we did not palpate any arteries in his lower legs. Next, pulses from his peroneal, tibialis anterior, and tibialis posterior arteries as well as the capillary refill, color, and temperature were compared between the injured and uninjured feet. Then, the paramedics brought in a 75-mm tibia that had fallen out of the body on the fishing boat. The bone was contaminated; therefore, we determined that the bone could not be returned to 
the tibia (Figure 2a, b and c). The peroneal, tibialis anterior, and tibialis posterior arteries were injured on 3D CT angiography (Figure 3a and b). Six hours after the injury, we debrided the soft tissues of the injury in the operating room. After debridement, the size of the soft-tissue defect was $40 \mathrm{~mm} \times 80 \mathrm{~mm}$. We decided that acute limb shortening and gradual lengthening would be a reasonable method for rapid revascularization. Accordingly, we shortened the fibula with a 75-mm osteotomy to match the length of the tibia. We resected and prepared a spike in the distal tibial fragment (Figure 4a). We crimped the fracture sufficiently and fixed it with an llizarov external fixator for temporary ankle joint-bridging fixation (Figure $4 \mathrm{~b}$ and $\mathrm{c}$ ). We reconstructed the anterior and posterior tibial arteries and veins with end-toend anastomosis.

Revascularization was completed six hours after injury, after which, the circulation in the injured foot improved. Now, the size of the soft-tissue defect was $20 \mathrm{~mm} \times 80 \mathrm{~mm}$. We used negative pressure wound therapy to address the soft-tissue defect (Figure 4d). After the patient gained consciousness following anesthesia, the ankle joint circulation was good and automatic movement of the ankle joint and toes was possible (Figure 4e). Although the patient had mild renal dysfunction, he did not undergo hemofiltration and recovered without any permanent organ damage.

Two days after the injury, we cleaned the open fracture again, performed additional debridement, and reapplied negative pressure wound therapy. Fourteen days after the injury, an osteotomy was performed at the proximal tibia with an llizarov external fixator for gradual limb lengthening (Figure 5a). Three weeks after the injury (one week after the osteotomy), we initiated gradual lengthening of the proximal tibia. We noted that the bone strength was weak at the time of wire insertion; therefore, we measured bone density and identified primary osteoporosis. A baseline dual-energy X-ray absorptiometry scan showed that his femoral neck bone mineral density was $0.441 \mathrm{~g} / \mathrm{cm}^{2}$ and T-Score of -3.3 standard deviation. He was started on a once-weekly injection of $56.5 \mu \mathrm{g}$ teriparatide. Furthermore, after osteotomy, treatment with a low-intensity pulsed ultrasound stimulation (LIPUS) device (SAFHS 2000, Exogen, Inc., Piscataway, NJ) was started for $20 \mathrm{~min} /$ day for the fracture and osteotomy sites. This device had a frequency of $1.5 \mathrm{MHz}$, a signal burst width of $200 \mu \mathrm{s}$, a signal repetition frequency of $1 \mathrm{kHz}$, and an intensity of $30 \mathrm{~mW} / \mathrm{cm}^{2}$. The patient was allowed to walk with full weight-bearing capacity immediately after the surgery (Figure $5 b$ ). He also began knee and ankle range of motion exercises. We performed bone lengthening at a rate of $0.75(0.25 \times 3) \mathrm{mm} /$ day. Radiography performed one year later revealed good callus formation (Figure 5c). The fixator was removed after one year. The patient returned to his original job as a fisherman two months after the fixator removal. At the 5-year follow-up after injury, radiographs showed good callus formation and bone union (Figure 6a, b, $c$ and d). The patient was independently mobile, with a knee range of motion of $0^{\circ}-140^{\circ}$, ankle dorsiflexion at $5^{\circ}$, and plantar flexion at $50^{\circ}$ (Figure $7 a, b$ and $c)$. During the 12 months with the fixator inserted, there were a few superficial pin-tract infections, which were treated with empirical oral antibiotics and daily pin-tract dressings.

\section{Discussion And Conclusions}


Treatment of high-energy open tibial fractures is challenging. Gustilo-Anderson type Illc open tibial fractures were mainly treated with amputation in the past [1]. The complication rates are high for Gustilo-Anderson type Illc open tibial fractures, which are associated with more severe soft-tissue loss and/or arterial injury requiring repair [2]; these complications include secondary amputation, nonunion, infection, and malunion [3-5]. The acceptance rate of amputation is poor in eastern-culture patients, especially in Japanese elderly patients [6]. Adaptation to a prosthesis is relatively easier in young amputees than in elderly amputees [7]. In our patient, there was a bone defect; soft-tissue defect; and peroneal, tibialis anterior, and tibialis posterior artery tears. The advantage of acute shortening is that it is easier to reconstruct the arteries and veins with end-to-end anastomosis. Furthermore, soft-tissue defects were smaller in genaral; therefore, function reconstruct was possible in our elderly patient, despite his presentation. In Gustilo-Anderson type IIIb open tibial fractures treated with acute shortening,gradual lengthening is usually subjected to a second-stage procedure performed after union of the fracture [8]. The main disadvantage of this approach is prolonged treatment duration. In Gustilo-Anderson type IIIc open tibial fractures, lengthening is delayed to prevent traction on vascular anastomoses as they heal, which may potentially risk the revascularization procedure. In our study, we performed early lengthening without causing any harm to vascular repair, as lengthening was performed at the proximal tibia most distant from the vascular injury. Management of open injuries of the limbs are challenging, as there are still many gray areas in decision-making regarding salvage, timing, and reconstruction type. As a result, there is still an unacceptable rate of secondary amputations, which leads to tremendous waste of resources and psychological devastation of the patient and their family [9]. In addition, limb salvage is more cost-effective than amputation and prosthesis use [10,11]. Our patient achieved a satisfactory functional status and avoided psychological trauma due to amputation; he was able to return to his original position as a fisherman.

It is difficult to reconstruct large bone defects in elderly patients with severe osteoporosis due to decreased bone formation. LIPUS has been used to treat leg lengthening $[12,13]$. Intermittent administration of human parathyroid hormone $(\mathrm{PTH})$ has an anabolic effect on the bone in humans and is expected to be a potent agent for fracture healing [14]. Several recent studies have revealed that intermittent treatment with PTH stimulates osteogenesis in experimental fracture healing of cortical bones and that the effects of PTH on cortical bone repair are site-specific. Aspenberg et al., in a prospective, randomized, double-blind study of conservative fracture treatment for 102 postmenopausal women with distal radial fractures, showed that the time to healing was shorter in patients who received $20 \mathrm{mg}$ teriparatide than in the placebo group patients [15]. Warden et al. reported that teriparatide and LIPUS have contrasting additive rather than synergistic effects during fracture healing [16]. Teriparatide primarily increased the callus bone mineral content without influencing its size, whereas LIPUS increased callus size without influencing the callus bone mineral content in rat models [16]. We have reported combined effect of teriparatide and low-intensity pulsed ultrasound for nonunion patients [17]. Furthermore, we have reported intractable fractures such as pathological fractures in patients with Alagille syndrome or nonunion after ankle fracture for Charcot arthropathy that was treated with LIPUS and an Ilizarov external fixator $[18,19]$. Early ambulation and immediate weight-bearing capacity may 
improve limb circulation and enhance the healing process, based on the fact that the speed of fracture healing is usually proportional to the amount of available circulation to and between fragments $[20,21]$.

One of the most important advantages of using llizarov external fixators is the excellent recorded knee and ankle range of motion within a short time after surgery. Active and passive movements of both the joints were allowed and encouraged during the entire course of treatment immediately after application of the frame. The main disadvantages of llizarov external fixators are that they are technically demanding and there is absolute necessity of adequate care of the frame. From our point of view, the fact that the patient could achieve immediate weight-bearing capacity and could be discharged and return to work is adequate justification for this procedure.

\section{Declarations}

Ethics approval and consent to participate

The patient received prior information before providing her written, informed consent in accordance with the Declaration of Helsinki. The article was approved by the ethics committee of Akita University Hospital (registration number 1970).

\section{Consent for Publication}

Written, informed consent was obtained from the patient for publication of this article and any accompanying images. A copy of the written consent is available for review by the Editor of this journal.

Availability of data and materials

The datasets used and/or analyzed during the current study are available from the corresponding author on reasonable request.

Competing interests

All authors declare that they have no competing interests.

Funding

The author(s) received no financial support for the research, authorship, and/or publication of this article. 
Authors' contributions

$\mathrm{KN}$ performed the surgery. MN helped with surgery and helped to draft the manuscript. MM and YS helped draft the manuscript. All authors read and approved the final manuscript.

Acknowledgements

Not applicable

\section{Abbreviations}

LIPUS: Low-intensity pulsed ultrasound stimulation

PTH: parathyroid hormone

\section{References}

1. Quirke TE, Sharma PK, Boss WK Jr, Oppenheim WC, Rauscher GE:Are type IIIC lower extremity injuries an indication for primary amputation. J Trauma. 1996,40(6):992-996.doi:10.1097/00005373199606000-00023.PMID:8656491 Review.

2. Gustilo RB, Mendoza RM, Williams DN: Problems in the management of type III (severe) open fractures: a new classification of type III open fractures. J Trauma.1984,24(8):742746.doi:10.1097/00005373-198408000-00009.PMID:6471139

3. Allen MJ, Nash JR,loannidies TT,Bell PR: Major vascular injuries associated with orthopaedic injuries to the lower limb. Ann R Coll Surg Engl. 1984,66(2):101-104.PMID:6703619 Free PMC article.

4. Howe HR Jr, Poole GV Jr, Hansen KJ, Clark T, Plonk GW, Koman LA, Pennell TC: Salvage of lower extremities following combined orthopedic and vascular trauma. A predictive salvage index. Am Surg. 1987,53(4):205-208.PMID:3579025

5. DiChristina DG, Riemer BL, Butterfield SL, Burke CJ 3rd, Herron MK, Phillips DJ: Femur fractures with femoral or popliteal artery injuries in blunt trauma. J Orthop Trauma. 1994,8(6):494503.PMID:7869164

6. Tunali O, Saglam Y, Balci HI, Kochai A, Sahbaz NA, Sayin OA, Yazicioglu O:Gustilo type IIIC open tibia fractures with vascular repair: minimum 2-year follow-up. Eur J Trauma Emerg Surg.2017,43(4): 505-512.doi:10.1007/s00068-016-0689-y.Epub 2016 Jun 7.PMID:27273011

7. Parmaksizoglu F, Koprulu AS, Unal MB, Cansu E:Early or delayed limb lengthening after acute shortening in the treatment of traumatic below-knee amputations and Gustilo and Anderson type IIIC 
open tibial fractures:The results of a case series.J Bone Joint Surg Br.2010,92(11):15631567.doi:10.1302/0301-620X.92B11.23500.PMID:21037353

8. Yokoyama K, Itoman M, Nakamura K, Uchino M,Tsukamoto T,Suzuki T: Primary shortening with secondary limb lengthening for Gustilo IIIB open tibial fractures: a report of six cases. J Trauma. 2006,61(1):172-180.doi:10.1097/01.ta.0000225049.41381.9d.PMID:16832267

9. Rajasekaran S, Sabapathy SR, Dheenadhayalan J, Sundararajan SR, Venkatramani H, Devendra A, Ramesh P, Srikanth KP: Ganga hospital open injury score in management of open injuries.Eur J Trauma Emerg Surg. 2015,41(1):3-15. doi: 10.1007/s00068-014-0465-9. Epub 2014 Nov 6.PMID: 26038161 Review.

10. Hertel R, Strebel N, Ganz R:Amputation versus reconstruction in traumatic defects of the leg: outcome and costs. J Orthop Trauma.1996,10(4):223-229.doi:10.1097/00005131-19960500000001.PMID:8723399

11. Williams MO:Long-term cost comparison of major limb salvage using the llizarov method versus amputation. Clin Orthop Relat Res. 1994,(301):156-158.PMID:8156666

12. Gebauer D, Correll J:Pulsed low-intensity ultrasound: a new salvage procedure for delayed unions and nonunions after leg lengthening in children. J Pediatr Orthop. 2005,25(6):750-

754.doi:10.1097/01bpo.0000173245.12184.7e.PMID:16294131

13. Sato W, Matsushita T, Nakamura K:Acceleration of increase in bone mineral content by low-intensity ultrasound energy in leg lengthening. J Ultrasound Med. 1999,18(10):699-

702.doi:10.7863/jum.1999.18.10.699.PMID:10511302

14. Nozaka K, Miyakoshi N, Kasukawa Y, Maekawa S, Noguchi H, Shimada Y: Intermittent administration of human parathyroid hormone enhances bone formation union at the site of cancellous bone osteotomy in normal and ovariectomized rats. Bone. 2008,42(1):90-97. doi:

10.1016/j.bone.2007.08.041.Epub 2007 Sep 14.PMID:17997377

15. Aspenberg P, Genant HK, Johansson T, Nino AJ, See K, Krohn K, García-Hernández PA, Recknor CP, Einhorn TA, Dalsky GP, Mitlak BH, Fierlinger A, Lakshmanan MC: Teriparatide for acceleration of fracture repair in humans: a prospective, randomized, double-blind study of 102 postmenopausal women with distal radial fractures. J Bone Miner Res. 2010,25(2):404-414. doi:

10.1359/jbmr.090731.PMID:19594305 Clinical Trial.

16. Warden SJ, Komatsu DE, Rydberg J, Bond JL, Hassett SM:Recombinant human parathyroid hormone (PTH 1-34) and low-intensity pulsed ultrasound have contrasting additive effects during fracture healing. Bone. 2009,44(3):485-494. doi: 10.1016/j.bone.2008.11.007.Epub 2008 Nov 21.PMID:19071238

17. Nozaka K,Shimada Y,Miyakoshi N,Yamada S,Hongo M,Kasukawa Y,Saito H,Kijima H: Combined effect of teriparatide and low-intensity pulsed ultrasound for nonunion: a case report. BMC Res Notes.2014,27(7):317.doi:10.1186/1756-0500-7-317.PMID:24886079 Free PMC article.

18. Nozaka K, Shimada Y,Miyakoshi N,Yamada S,Kasukawa Y,Noguchi A: Pathological fracture of the femur in Alagille syndrome that was treated with low-intensity pulsed ultrasound stimulation and an 
Ilizarov ring fixator: a case report. BMC Musculoskelet Disord. 2014,8(15):225. doi: 10.1186/14712474-15-225.PMID:25004954 Free PMC article.

19. Nozaka K, Shimada Y,Kimura Y,Yamada S,Kashiwagura T,Sakuraba T,Wakabayashi I: Successful treatment of nonunion with an Ilizarov ring fixator after ankle fracture for Charcot arthropathy: a case report囚BMC Res Notes. 2014,7(7):503. doi: 10.1186/1756-0500-7-503.PMID:25103697 Free PMC article.

20. El-Sayed M, Atef A: Management of simple (types A and B) closed tibial shaft fractures using percutaneous lag-screw fixation and llizarov external fixation in adults. Int Orthop. 2012,36(10):2133-2138. doi:10.1007/s00264-012-1620-8.Epub 2012 Jul 21.PMID:22820713 Free PMC article. Clinical trial.

21. Nozaka K,Miyakoshi N,Saito H,Chida S,Tsuchie H,Shimada Y: Effectiveness of Ilizarov external fixation in elderly patients with pilon fractures. J Orthop Sci. 2021, 26(2):254-260.doi: 10.1016/j.jos.2020.02.018. Epub 2020 Mar 26. PMID:32223990 Free article.

\section{Figures}

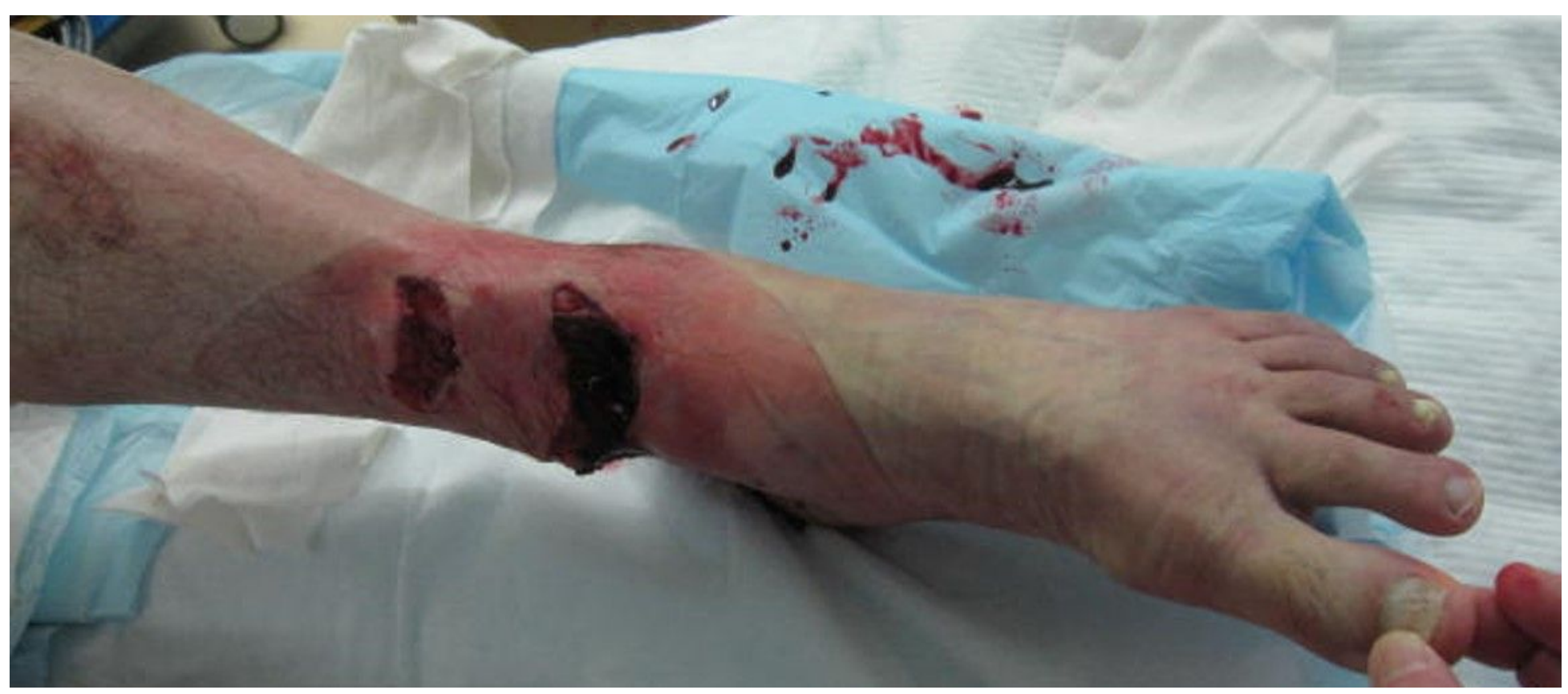

\section{Figure 1}

Two large soft-tissue defects in the medial left ankle 


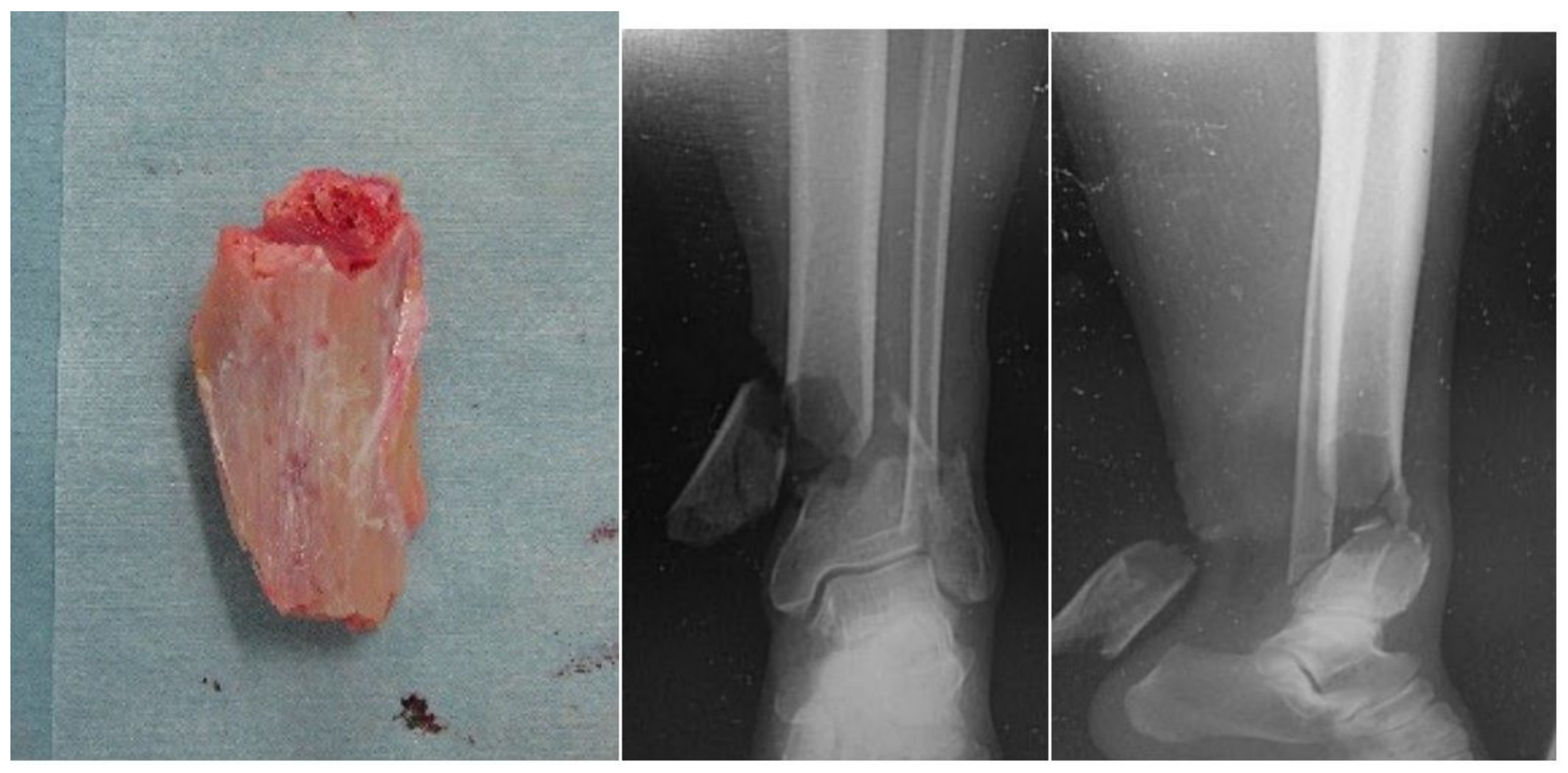

Figure 2

(a) The contaminated large bone that fell out of the body; (b and c) X-ray images taken in the emergency room 


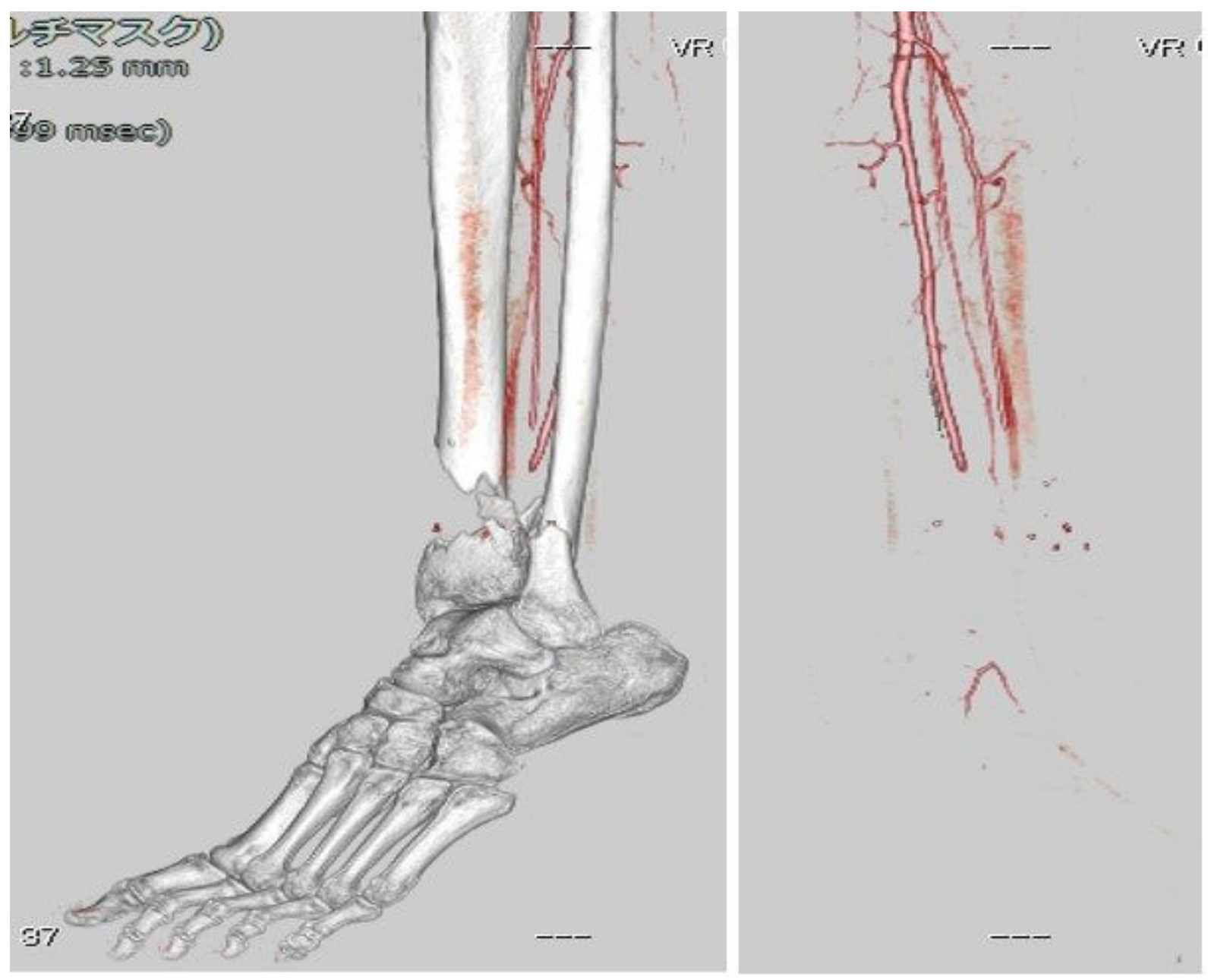

Figure 3

(a) 3D computed tomography angiography image with the bone; (b) 3D computed tomography angiography image without the bone 3D, three-dimensional 


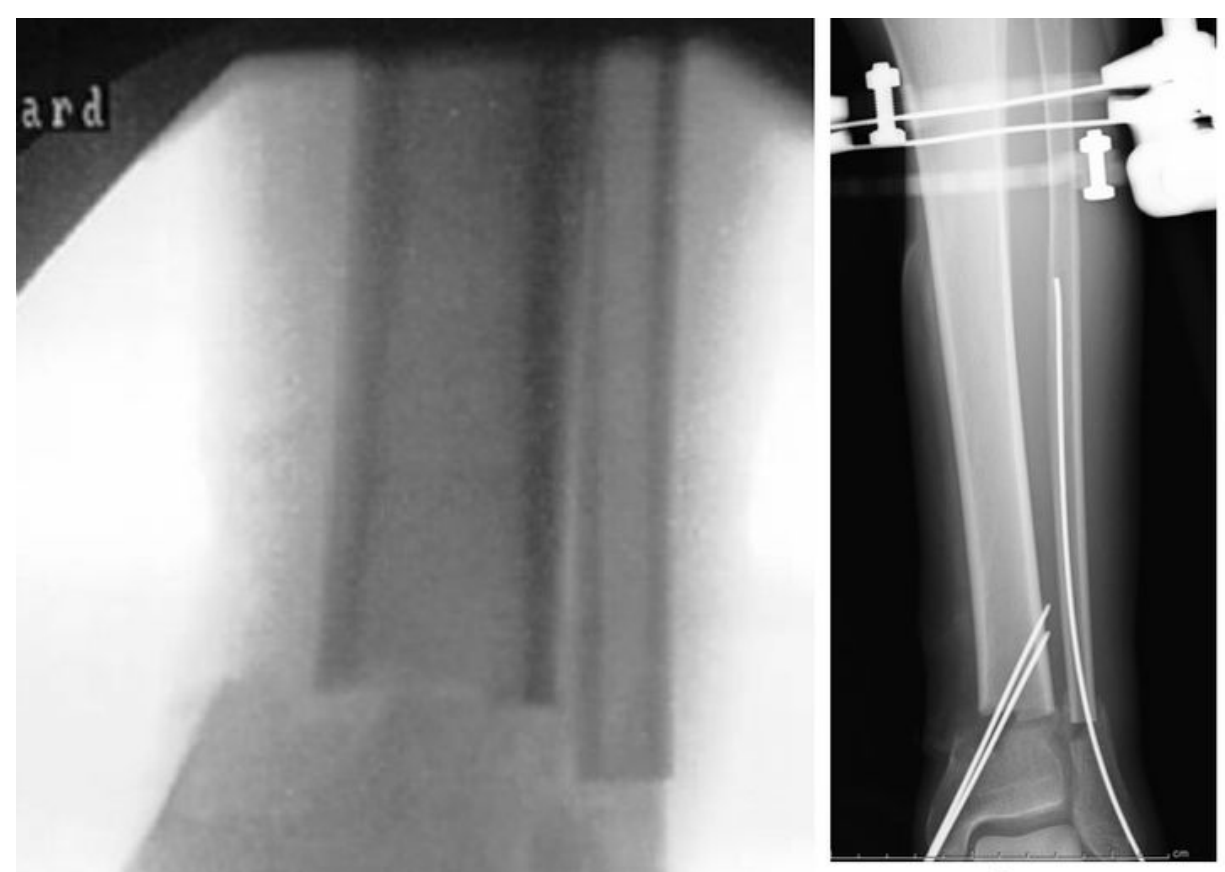

B

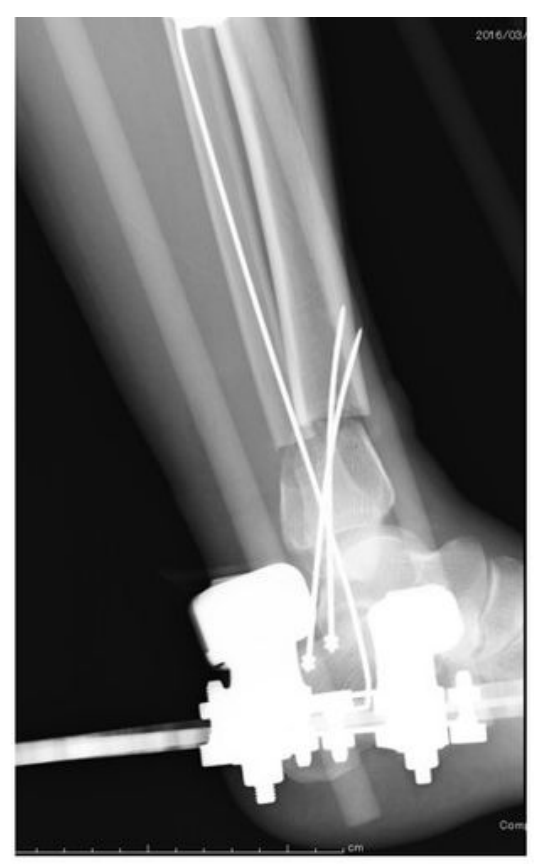

C

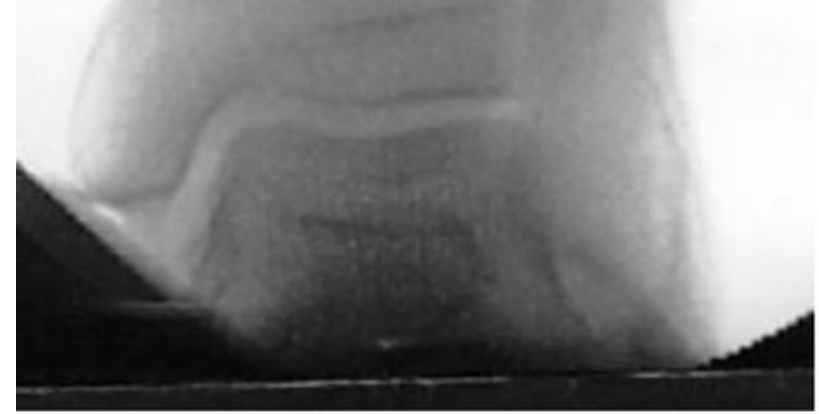

A

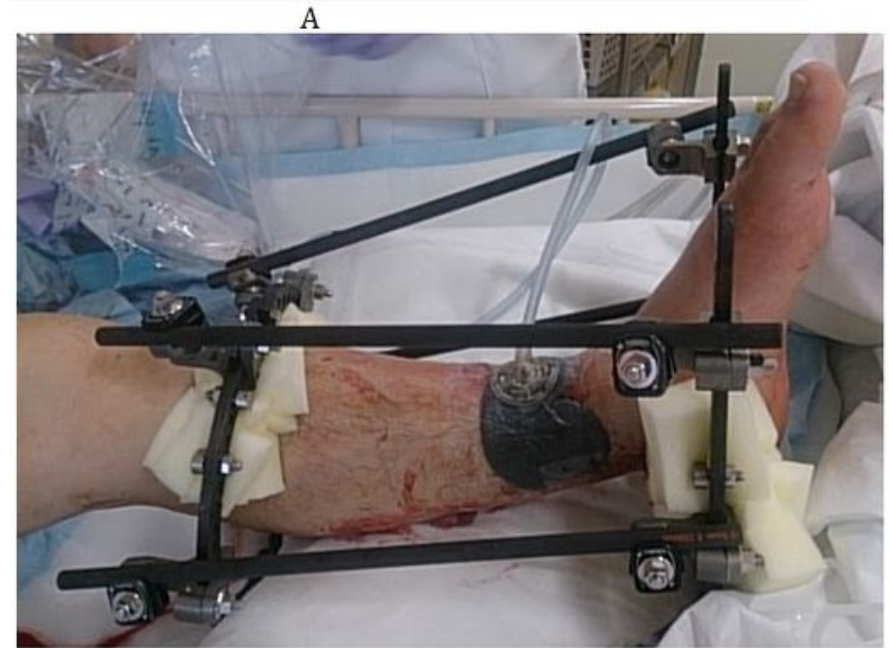

D

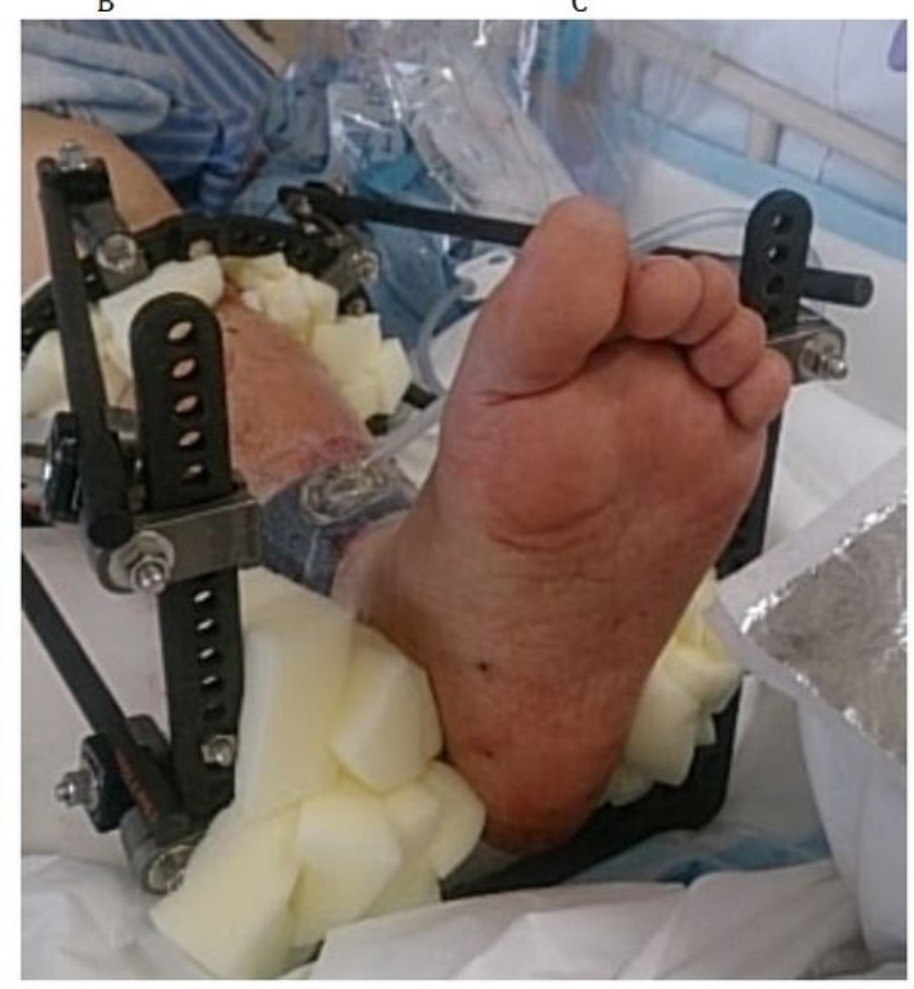

E

Figure 4

(a) Shortened fibula with a 75-mm osteotomy to match the length of the tibia; (b and c) the fibula was fixed with an Ilizarov external fixator for temporary ankle joint-bridging fixation; (d and e) clinical photograph of the fibula was fixed with an llizarov external fixator for temporary ankle joint-bridging fixation 

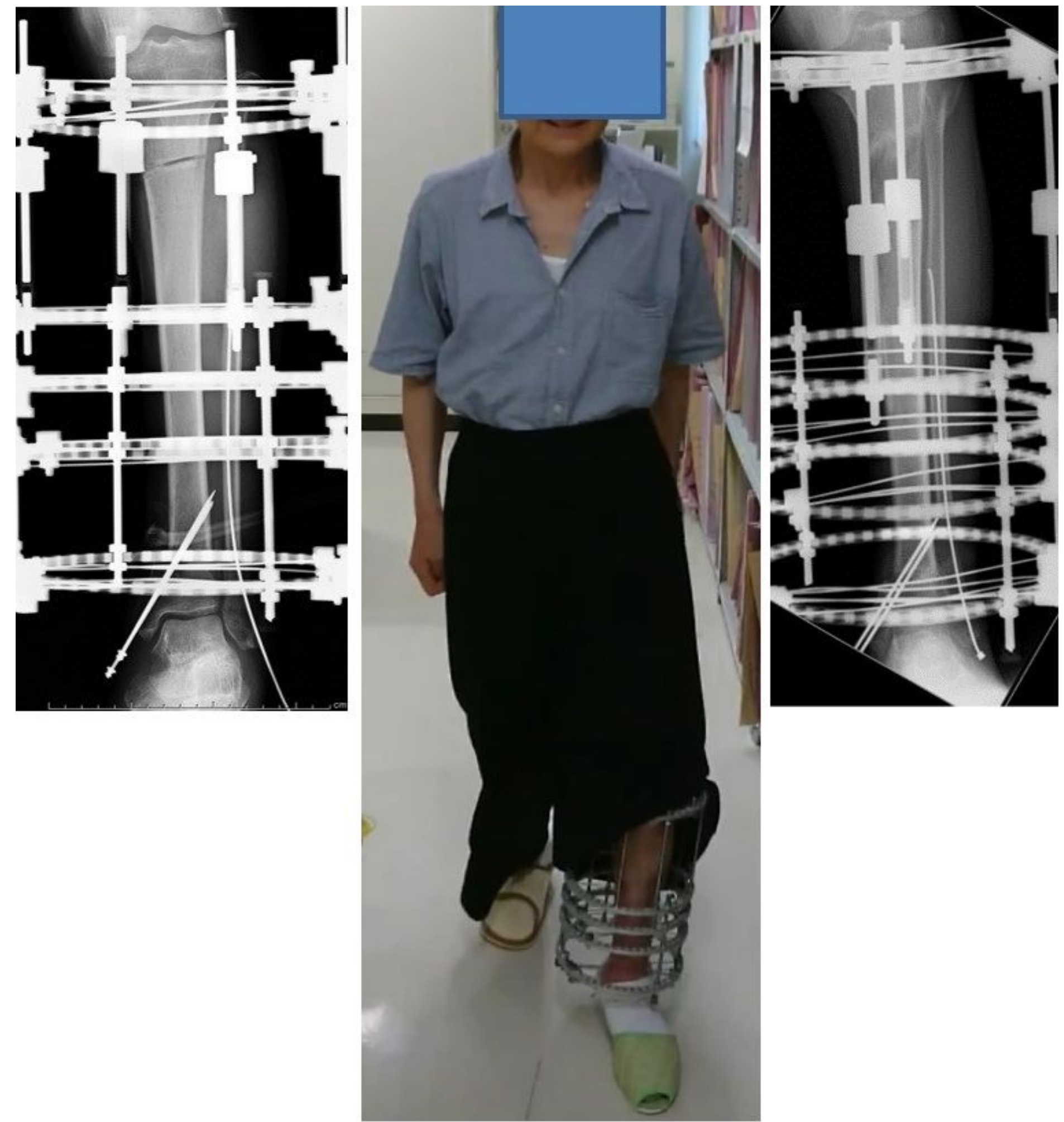

\section{Figure 5}

(a) Osteotomy at the proximal tibia with an llizarov external fixator for gradual lengthening; (b) bone lengthening at a rate of $0.75(0.25 \times 3) \mathrm{mm} /$ day; (c) walking with full weight-bearing capacity immediately after surgery 


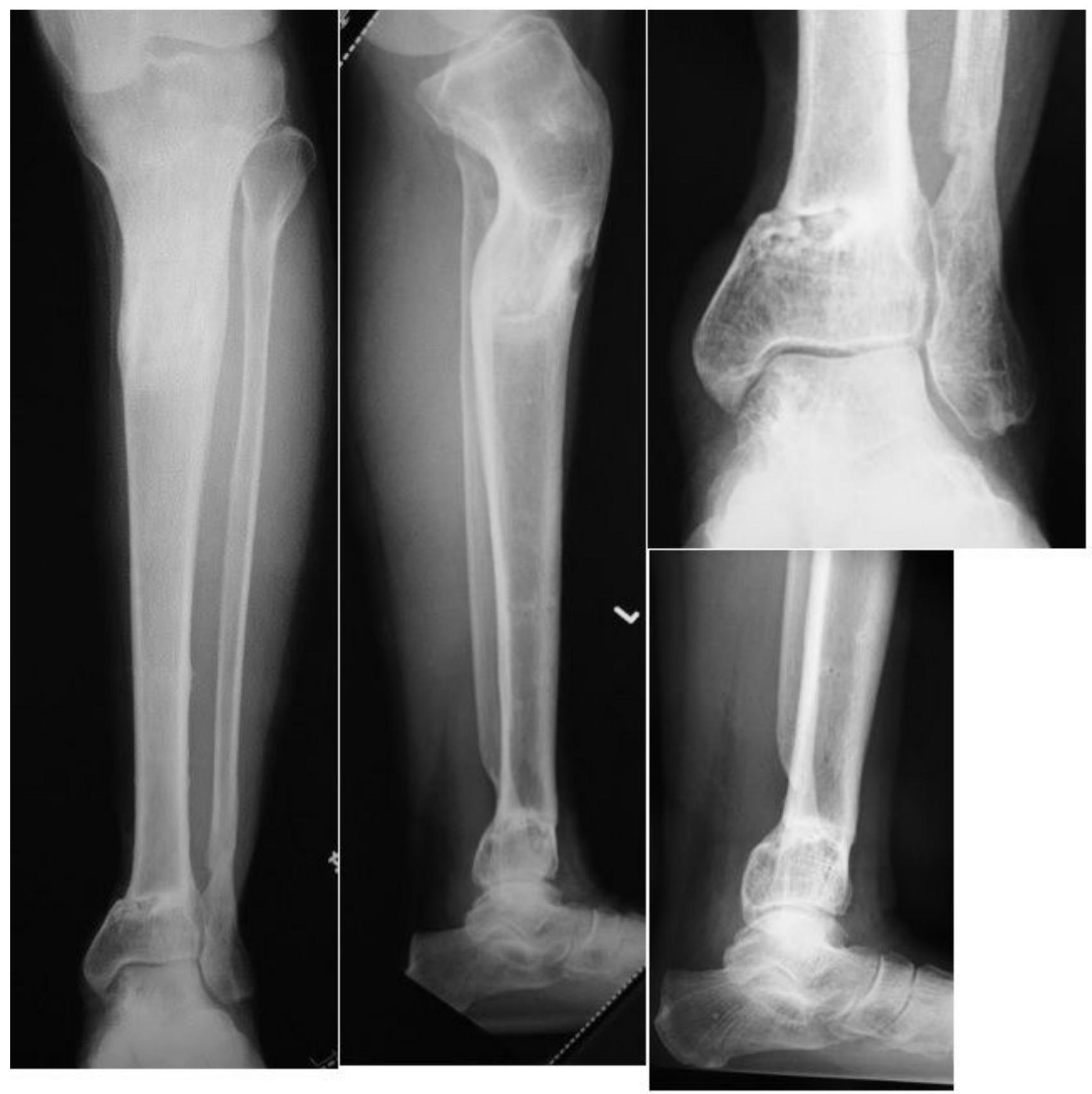

Figure 6

(a, b, c and d) X-ray images taken at postoperative 5-year follow-up 

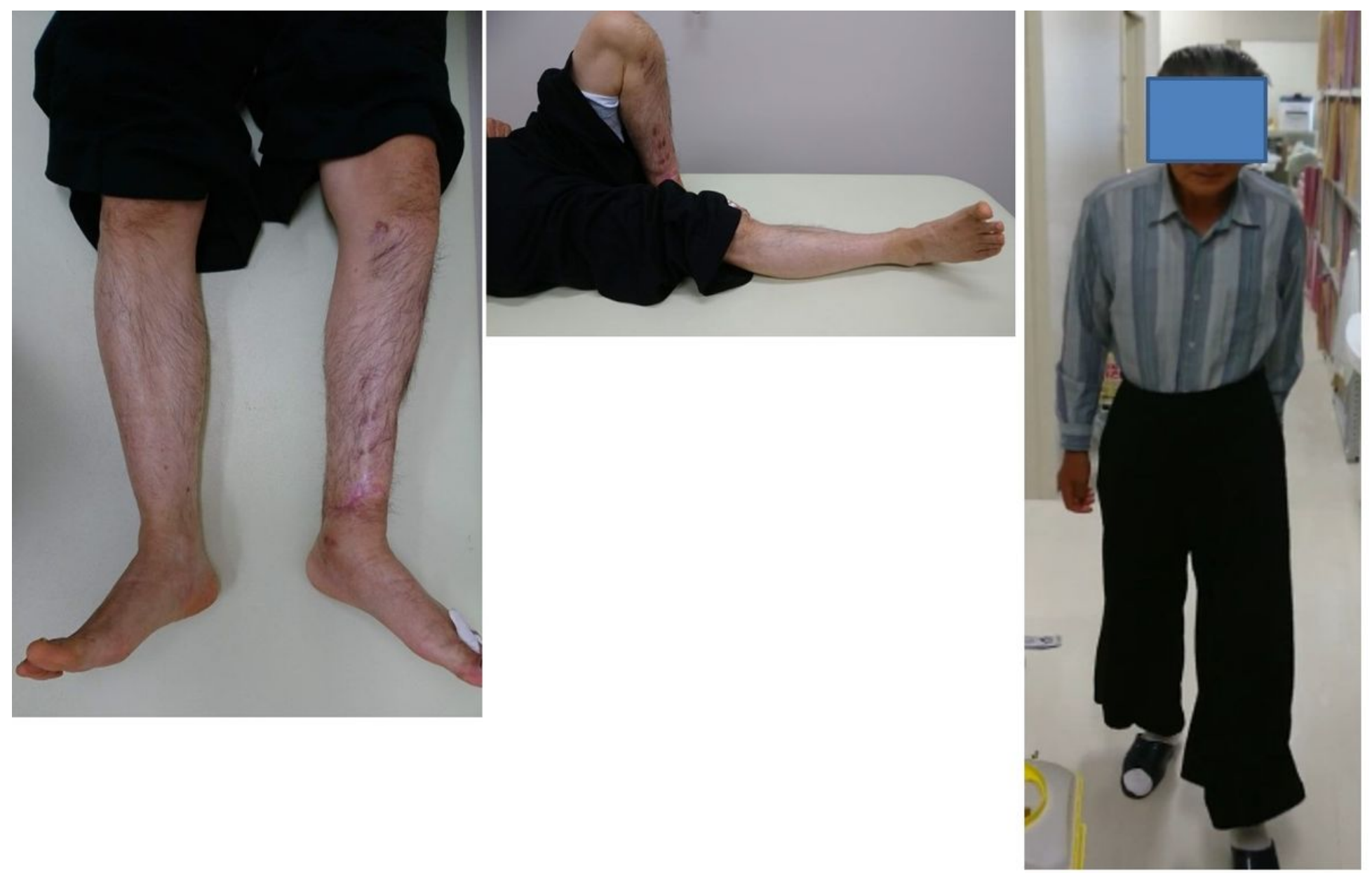

Figure 7

(a, b, and c) Clinical photograph at postoperative 5-year follow-up

\section{Supplementary Files}

This is a list of supplementary files associated with this preprint. Click to download.

- renamed9e4c4.pdf 